Article

\title{
Goldsmiths Musical Sophistication Index (Gold-MSI): Portuguese version and associations with socio-demographic factors, personality and music preferences
}

Psychology of Music $1-13$

(C) The Author(s) 2018 Article reuse guidelines: sagepub.com/journals-permissions DOI: $10.1177 / 0305735618801997$ journals.sagepub.com/home/pom

BSAGE

\author{
César F. Limal',2,3, Ana Isabel Correia², \\ Daniel Müllensiefen ${ }^{4}$ and São Luís Castro ${ }^{2}$
}

\begin{abstract}
The Goldsmiths Musical Sophistication Index (Gold-MSI) was recently proposed as a self-report measure of musical skills and behaviors in the general population. Although it is becoming a widely used tool, relatively little is known about its correlates, and adaptations into different languages will be crucial for cross-cultural comparisons and to allow for use beyond the original validation context. In this study, we adapted the Gold-MSI for use with Portuguese speaking individuals and evaluated it with a Portuguese sample $(N=408$; age range $=17-66$ years; 306 women $)$. We demonstrate that the Portuguese version of the Gold-MSI has appropriate psychometric properties, including good internal consistency and very good test-retest reliability. This was observed for the five subscales and for the general musical sophistication index ( $\alpha$ values $\geqslant 0.82, r$ values $\geqslant 0.84$ ). Using confirmatory factor analysis, the expected underlying factor structure was also confirmed. In addition, we identified associations between individual differences on the Gold-MSI and socio-demographic factors (age, sex, education, socio-economic status), personality traits, and music preferences. The Portuguese Gold-MSI is freely available, and it offers a reliable and valid tool that can contribute to the refined assessment of musical sophistication in a range of research contexts.
\end{abstract}

\section{Keywords}

Gold-MSI, musical sophistication, musicality, Portuguese, psychometric properties

\footnotetext{
${ }^{1}$ Instituto Universitário de Lisboa (ISCTE-IUL), Lisboa, Portugal

${ }^{2}$ Centro de Psicologia da Universidade do Porto, Portugal

${ }^{3}$ University College London, UK

${ }^{4}$ Goldsmiths, University of London, UK
}

\section{Corresponding author:}

César F. Lima, Instituto Universitário de Lisboa (ISCTE-IUL), Avenida das Forças Armadas, 1649-026, Lisboa,

Portugal.

Email: cesar.lima@iscte-iul.pt 
Musical behaviors and skills vary widely, both among individuals and across cultural groups. In scientific research and in Western societies more broadly, the assessment of musicality and musical achievements typically emphasizes the ability to play an instrument, or the expertise of formally trained professional musicians. For instance, a large body of work examines differences between professional musicians and "non-musicians" in a range of musical and nonmusical abilities, or the impact of learning how to play an instrument in behavior, cognition, and brain functioning (Coffey, Mogilever, \& Zatorre, 2017; Herholz \& Zatorre, 2012; Lima \& Castro, 2011; Moreno \& Bidelman, 2014). This approach has been highly informative, but it does not do justice to the variety of ways people can engage with music and the multifaceted nature of musical abilities. It also does not capture individual differences in musicality beyond highly specialized groups, i.e., it neglects variation in the general population, and it is known that some music capacities can be achieved without formal training, through exposure and implicit learning (e.g., Bigand \& Poulin-Charronnat, 2006).

To address these issues, Müllensiefen, Gingras, Musil, and Stewart (2014) developed a selfreport instrument that measures "musical sophistication" in a comprehensive way, considering a range of musical skills and behaviors in addition to instrumental expertise- the Goldsmiths Musical Sophistication Index (Gold-MSI). Musical sophistication is conceptualized as a psychometric construct that refers to music-related skills, achievements, and expertise, and associated behaviors across a wide range of facets, which are reflected in the different subscales of this questionnaire. The development of musical sophistication is thought to occur via active engagement with music in its multiple forms, and higher levels of sophistication would be generally characterized by exerting musical skills and behaviors more frequently; greater accuracy, ease or effect of musical behaviors when applied; and greater and more varied repertoire of musical behavior patterns. The Gold-MSI includes items that apply to any musical style and any age group, and that cover a variety of potential behaviors of interest as they occur in daily life. It can thus be used equally well with performing musicians with different levels of formal musical training, individuals who use music in functional ways (e.g., music educators, producers, disk-jockeys), or with individuals from the general population, without explicit musical training. The subscales of the Gold-MSI comprise active engagement, which assesses musical engagement behaviors such as "I spend a lot of my free time doing music-related activities"; perceptual abilities, which assesses music skills such as "I can tell when people sing or play out of time with the beat"; musical training, which assesses the extent of musical training and practice with items such as "I engaged in regular daily practice of a musical instrument including voice for _ years"; singing abilities, which assesses activities related to singing such as "I am able to hit the right notes when I sing along with a recording"; and emotions, which assesses behaviors related to emotional responses to music such as "I often pick certain music to motivate or excite me." In addition to indexing these distinct dimensions, the Gold-MSI also provides a global measure of musical sophistication, based on a subset of items from all subscales.

Based on a large sample of English-speaking participants, Müllensiefen et al. (2014) established that the Gold-MSI possesses appropriate psychometric properties, including good internal consistency, very good test-retest reliability, and appropriate convergent and discriminant validities. They also found that, despite being a self-report measure, individual differences in the Gold-MSI correlate to performance-based levels of music skills, as assessed by the Gordon's Advanced Measures of Music Audiation and by two listening tests of melodic memory and musical beat perception. Additionally, positive correlations with personality traits were observed, particularly with openness and extraversion, and socio-demographic predictors were identified, such as age, education, and occupation. Since it was published, the Gold-MSI has 
attracted broad interest, as indicated by its growing use across a wide range of research settings, including neuroscientific and behavioral work with musicians (e.g., Schaal, Banissy, \& Lange, 2015; Schaal, Krause, et al., 2015), personality (e.g., Greenberg, Müllensiefen, Lamb, \& Rentfrow, 2015), music psychology (e.g., Hadley, Sturt, Eerola, \& Pickering, 2018; Hansen, Vuust, \& Pearce, 2016; Jakubowski, Farrugia, \& Stewart, 2016; Jakubowski, Halpern, Grierson, \& Stewart, 2015), emotion (e.g., Taruffi, Allen, Downing, \& Heaton, 2017), and auditory attention research (e.g., Bauer, Jaeger, Thorne, Bendixen, \& Debener, 2015; Bleichner, Mirkovic, \& Debener, 2016).

Adaptations of the Gold-MSI for use in different linguistic and cultural contexts will be crucial, both for cross-cultural research on music behaviors and skills, and to allow for a broader use of this tool beyond the original context in which it was developed (United Kingdom). The Gold-MSI has been translated into German (Schaal, Bauer, \& Müllensiefen, 2014), Danish, and French, but a Portuguese version has been lacking.

\section{The current study}

In the current study, we translated the Gold-MSI to European Portuguese (Gold-MSI-P) and evaluated it with a diverse Portuguese sample that included undergraduate students and individuals from the general population, covering a wide range of age and education levels. We determined the internal consistency, test-retest reliability, and factor structure adequacy of the newly developed Gold-MSI-P. Participants also completed measures of socio-economic status (SES), personality traits, and music preferences. This was for the purpose of advancing knowledge on the correlates of the Gold-MSI, which remain poorly investigated. As for sociodemographic and personality variables, we expected to find similar associations to those found in previous studies with the Gold-MSI (Müllensiefen et al., 2014; Schaal et al., 2014). For instance, we hypothesized that younger participants would report higher levels of musical sophistication, and we also hypothesized that openness and extraversion would be associated with higher Gold-MSI scores. As for music preferences, associations have been found between liking particular musical genres and personality (Rentfrow \& Gosling, 2003; Zweigenhaft, 2008), but potential associations with musical sophistication remain unknown. Here we explore associations between music preferences and individual differences in the Gold-MSI for the first time. Since the Gold-MSI was originally designed to assess musical sophistication regardless of preferences, familiarity or engagement with particular genres of music, we expect associations between liking music and sophistication to be general, i.e., not strongly tied to specific genres of music. However, a potential exception would be the musical training subscale, which could be linked to a more specific preference for "art music" (e.g., classical music), as formal musical training is most common for this kind of music in Western societies.

\section{Method}

\section{Participants}

A total of 474 individuals initially took part in the study. ${ }^{1}$ From this sample, we excluded participants who did not complete all the Gold-MSI-P items $(n=53)$, were not Portuguese nationals $(n=12)$, or had missing demographic information $(n=1)$. This excluded 66 participants and left 408 in the final sample (306 female, 75\%). These were aged between 17 and 66 years $(M=33.0, S D=14.4)$ and were all native speakers of European Portuguese. According to the European Socio-Economic Classification (ESeC; Rose \& Harrison, 2007), which formally 
evaluates SES, most participants fell into high socioeconomic classes (classes 1 and 2, 51.8\%; classes 3-6, 30.4\%; classes 7-10, 17.8\%). In terms of education, most participants completed secondary education (12 years; $53.2 \%)$ or a bachelor's degree $(27.7 \%$; nine or fewer years of education, $11.5 \%$; master's degree, 6.1\%; Ph.D., 1.5\%). Part of the sample consisted of undergraduate students, but for generalizability we also ensured that a significant number of participants were from the general population $(n=218,46.6 \%)$. These were recruited using a snowball sampling technique. See online Appendix A for additional details concerning the socio-demographic characteristics of the sample.

To assess test-retest reliability, 79 participants randomly selected from the full sample completed the Gold-MSI-P and a music preferences questionnaire again, four weeks after the first testing session.

Written informed consent was collected from all participants, and ethical approval was obtained from the Departmental Ethics Committee, Faculty of Psychology and Education Sciences, University of Porto (reference 3-1/2017). Participants were not paid for their participation, and the questionnaires were completed either in individual sessions or in class groups, using a paper-and-pencil format.

\section{Gold-MSI and development of its Portuguese version}

The Gold-MSI contains a total of 38 items (Müllensiefen et al., 2014). For 31 of them, participants indicate their level of agreement with statements (e.g., "I can sing or play music from memory") using a Likert-type scale from 1 (completely disagree) to 7 (completely agree). For the remaining seven items, participants use ordinal scales with seven response alternatives that vary depending on the musical behavior assessed (e.g., "I can play [number from 0 to ' 6 or more'] instruments"). The items are grouped into five subscales: active engagement, nine items; perceptual abilities, nine items; musical training, seven items; singing abilities, seven items; and emotions, six items. A general factor of musical sophistication has also been identified, consisting of 18 items that include exemplars from all the five subscales. The Gold-MSI can thus be used as a multidimensional instrument, covering different facets of musical behavior, or as a unidimensional one, assessing musical sophistication more generally.

The Gold-MSI-P was developed as follows (e.g., Hambleton, 2005, for guidelines for adapting tests into multiple languages). First, the items of the original English Gold-MSI were translated to Portuguese, independently by two translators. They were native speakers of European Portuguese, fluent in English, experienced in the adaptation of questionnaires, and experts in music psychology (C.F.L. and S.L.C.). Second, disagreements between the two translators were sorted out, and a single version was obtained. Third, this version was shown to two lab colleagues to evaluate the items for clarity and naturalness of language and to discuss the equivalence between the original and the new version. Fourth, the Gold-MSI-P was translated back to English by an English native speaker who was fluent in Portuguese and had subject knowledge. Inconsistencies between the back-translation and the original Gold-MSI were sorted out between the three translators, and equivalence across languages was additionally discussed with D.M., leading author of the original questionnaire. The emphasis was placed on ensuring conceptual equivalence, rather than a literal translation. Fifth, in a pilot study, 10 participants completed the Gold-MSI-P, and they all confirmed that the items were clear. The Portuguese items are listed in online Appendix B, and the final version of the Gold-MSI-P is freely available from http://cesarflima.com/publications/or https://s.up.pt/mza2. 


\section{Additional measures}

SES. SES was assessed through a formal inventory, the ESeC (Rose \& Harrison, 2007). The $\mathrm{ESeC}$ is based on the characteristics of the occupational status, including the occupation itself, the employment status (whether the person is an employer, self-employed or employee), the number of employees at the workplace, and whether the person has supervising responsibilities. It has rules to cover the whole adult population and allows for the classification of individuals into 10 classes, from 1 ("the higher salariat") to 10 ("unemployed").

Thirty-seven participants had missing data on their SES. These participants were excluded from the analyses that included this variable.

Big-Five Inventory. The Big-Five Inventory (BFI) is a questionnaire that evaluates the "Big Five" dimensions of personality (John \& Srivastava, 1999; McCrae \& Costa, 1987; Portuguese version, Brito-Costa et al., 2015). It comprises 44 short phrases (e.g., "Is full of energy"; "Is generally trusting”, which are categorized into five major personality factors: extroversion, agreeableness, openness, conscientiousness, and neuroticism. Each item is rated on a 5-point scale, from 1 (totally disagree) to 5 (totally agree). Internal consistency values for the BFI were acceptable to good in the current dataset $(\alpha=0.80$ on average, ranging from $\alpha=0.66$ for agreeableness to $\alpha=0.87$ for extroversion).

Eight participants had missing data on the BFI. These participants were excluded from the analyses that included this variable.

Short Test of Music Preferences. The Short Test of Music Preferences (STOMP) is a questionnaire that assesses individual differences in preferences for musical genres (Rentfrow \& Gosling, 2003). For brevity of the testing session, we used the original 14-item STOMP (which we have translated to Portuguese beforehand, see online Appendix C) and not the revised 23-item version. Each item is rated on a 7-point scale, from 1 (dislike strongly) to 7 (like strongly), and musical genres can be grouped into the four factors: Reflective and Complex (four items; e.g., classical), Intense and Rebellious (three items; e.g., rock), Upbeat and Conventional (four items; e.g., pop), and Energetic and Rhythmic (three items; e.g., dance/electronica). We obtained testretest reliability values comparable to those in the original study $(r=0.78$ on average, ranging from $r=0.69$ for Upbeat and Conventional to $r=0.88$ for Reflective and Complex). Additionally, all factors showed acceptable mean inter-item correlations, ranging from $r=0.18$ to $r=$ 0.35 (Clark \& Watson, 1995).

Twenty-four participants had missing data on the STOMP. These participants were excluded from the analyses that included this variable.

\section{Statistical analysis}

We calculated four different indices of internal consistency, including Cronbach's alpha (Cronbach, 1951), McDonald's omega (Zinbarg, Revelle, Yovel, \& Li, 2005), Guttman's Lambda 6 (Guttman, 1945), and mean inter-item correlations. This was done for each of the five GoldMSI-P subscales and for the general musical sophistication factor.

To assess the degree to which the data from the Portuguese sample fit the structure of the bi-factor model as reported in Müllensiefen et al. (2014; Model 2, "Schmid-Leiman" variant), we conducted a confirmatory factor analysis using the exact same factor structure and employing a robust maximum likelihood estimator from the R package "lavaan" (Rosseel, 2012). Four indices were used to assess model fit: the incremental comparative fit index (CFI) 
and Tucker-Lewis index (TLI), and the absolute fit indices root mean square error of approximation (RMSEA) and standardized root mean square residual (SRMR).

Pearson correlation analyses were conducted to assess associations between the Gold-MSI-P subscales, associations between responses at two time points (test-retest reliability), as well as associations with age, personality traits, and music preferences. Kendall's tau-b correlation analyses were conducted to assess associations between the Gold-MSI-P, education level (five levels), and SES (10 levels). A correlational approach was used to examine associations between musical sophistication and other variables (personality, music preferences, and SES), as it is unclear if there is a causal relationship between these variables and what the directions of causes and effects are (Müllensiefen et al., 2014).

Independent samples $t$-tests were conducted to assess potential differences between men and women in the Gold-MSI-P.

Correlations and $t$-tests were statistically evaluated via Bayesian inference, by estimating a Bayes Factor $(B F)$ statistic, which grades the amount of evidence that the data provide for the alternative as compared to the null hypotheses $\left(B F_{10}\right)$. These analyses were conducted using JASP Version 0.8.4 (JASP Team, 2017). Both correlation analyses and $t$-tests were two-sided, and the default priors were used (correlations, stretched beta prior width $=1$; $t$-tests, zerocentered Cauchy prior with scale parameter 0.707; Wagenmakers et al., 2017; Wagenmakers, Verhagen, \& Ly, 2016). $B F_{10}$ values were interpreted following Jeffreys' guidelines: values between 1 and 3 are considered as anecdotal evidence for the alternative hypothesis; between 3 and 10 as substantial evidence; between 10 and 30 as strong evidence; between 30 and 100 as very strong evidence; and over 100 as decisive evidence (Jarosz \& Wiley, 2014; Jeffreys, 1961). A $B F_{10}<1$ is evidence in favor of the null hypothesis. For completeness, we also evaluated significance based on the standard frequentist approach, reporting significant results $(p<$ 0.05) after Bonferroni adjustments for multiple comparisons.

\section{Results}

\section{Summary statistics and internal consistency reliability}

Table 1 shows summary statistics and measures of internal consistency and reliability for each of the Gold-MSI-P subscales and for the general sophistication factor (the distribution of the data is depicted in Figure 1). As can be seen in the table, all subscales possess good or excellent estimates across all measures, namely, Cronbach's $\alpha$ (range from 0.82 to 0.91), Guttman's $\lambda 6$ (range from 0.81 to 0.93 ), McDonald's $\omega$ (range from 0.83 to 0.91 ), inter-item correlation (range from 0.36 to 0.56 ), and mean item-total correlations (range from 0.54 to 0.57; Clark \& Watson, 1995; Field, 2005; Revelle \& Zinbarg, 2009). These internal consistency values are similar to those obtained for the original Gold-MSI (Müllensiefen et al., 2014) and for the German version (Schaal et al., 2014). Summary statistics, including means and the amount of inter-individual variation, are also comparable to those observed for previous versions of the questionnaire.

Table 2 shows the correlations between the Gold-MSI-P subscales. As expected, all subscales were significantly correlated with each other, with coefficients ranging from 0.38 to 0.74 . Similar findings were previously observed for the Gold-MSI (range from 0.49 to 0.81 , Müllensiefen et al., 2014; range from 0.37 to 0.70, Schaal et al., 2014), and they suggest that the subscales cover related, but not identical, constructs.

We also examined the data for each item individually: all items were able to capture individual differences (range from 1.10 to 2.10); item-total correlation coefficients ranged 
Table I. Summary statistics and reliability for the Gold-MSI-P subscales and general sophistication factor.

\begin{tabular}{lllllll}
\hline & $\begin{array}{l}\text { Active } \\
\text { engagement }\end{array}$ & $\begin{array}{l}\text { Perceptual } \\
\text { abilities }\end{array}$ & $\begin{array}{l}\text { Musical } \\
\text { training }\end{array}$ & $\begin{array}{l}\text { Singing } \\
\text { abilities }\end{array}$ & Emotions & $\begin{array}{l}\text { General } \\
\text { sophistication }\end{array}$ \\
\hline Mean (SD) & $3.67(1.15)$ & $4.95(0.97)$ & $2.64(1.45)$ & $3.81(1.21)$ & $5.22(1.06)$ & $3.60(1.07)$ \\
Minimum & 1.00 & 1.56 & 0.29 & 1.00 & 1.33 & 1.00 \\
Maximum & 6.56 & 7.00 & 6.71 & 7.00 & 7.00 & 6.72 \\
Cronbach's $\alpha$ & 0.85 & 0.85 & 0.89 & 0.83 & 0.82 & 0.91 \\
Guttman's $\lambda 6$ & 0.85 & 0.85 & 0.91 & 0.83 & 0.81 & 0.93 \\
$\begin{array}{l}\text { McDonald's } \omega \\
\text { Inter-item }\end{array}$ & 0.85 & 0.85 & 0.90 & 0.84 & 0.83 & 0.91 \\
$\begin{array}{l}\text { correlation } \\
\text { Mean item-total } \\
\text { correlation }\end{array}$ & 0.38 & 0.38 & 0.56 & 0.41 & 0.44 & 0.36 \\
\hline
\end{tabular}

Gold-MSP-P: Goldsmiths Musical Sophistication Index, Portuguese version; SD: standard deviation.

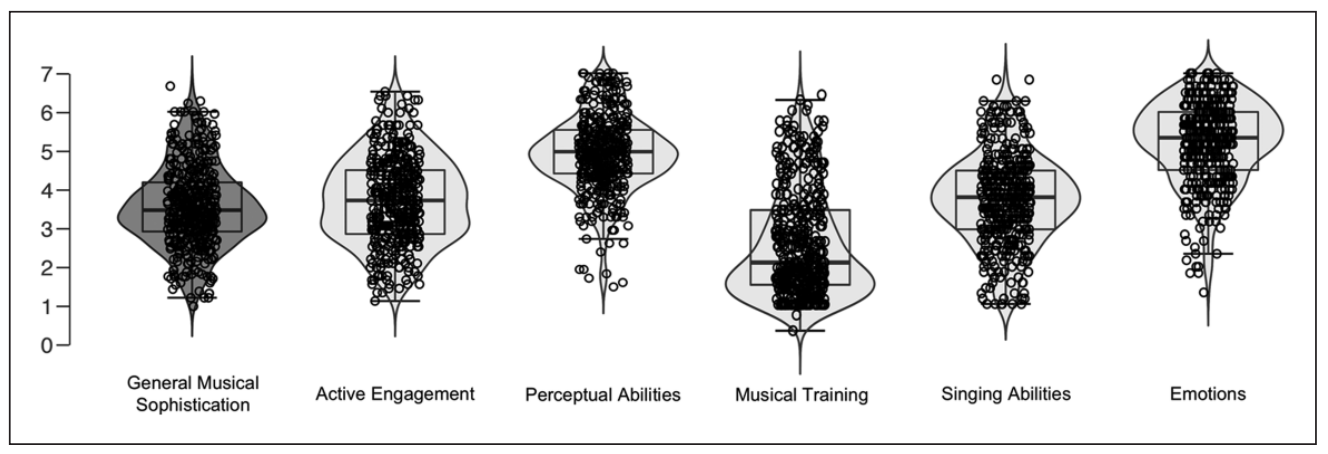

Figure I. Distribution of the data for the Gold-MSI-P subscales and general sophistication factor. Gold-MSI-P: Goldsmiths Musical Sophistication Index, Portuguese version.

Table 2. Correlations between the Gold-MSI-P subscales.

\begin{tabular}{llllll}
\hline & $\begin{array}{l}\text { Active } \\
\text { engagement }\end{array}$ & $\begin{array}{l}\text { Perceptual } \\
\text { abilities }\end{array}$ & $\begin{array}{l}\text { Musical } \\
\text { training }\end{array}$ & $\begin{array}{l}\text { Singing } \\
\text { abilities }\end{array}$ & Emotions \\
\hline Active engagement & - & - & - & - & - \\
Perceptual abilities & 0.63 & - & - & - & - \\
Musical training & 0.46 & 0.51 & - & - & - \\
Singing abilities & 0.60 & 0.64 & 0.55 & - & - \\
Emotions & 0.74 & 0.68 & 0.38 & 0.52 & -
\end{tabular}

Note: $B F_{10}>100$ for all correlations (also significant at the corrected $p<0.00 \mathrm{I}$ ).

Gold-MSP-P: Goldsmiths Musical Sophistication Index, Portuguese version.

from 0.25 to 0.72 , indicating that all the items are consistent with the overall scale and are, therefore, representative of the construct they are measuring (Clark \& Watson, 1995; Churchill, 1979; Field, 2005); and values of skewness and kurtosis were always below 2 and 7 , respectively (skewness ranges from -1.86 to 1.62 ; kurtosis ranges from -1.26 to 3.92 ), 
Table 3. Test-retest correlations for the subscales of the Gold-MSI-P $(n=79)$.

\begin{tabular}{llll}
\hline & Test & Retest & Test-retest \\
& $M(S D)$ & $M(S D)$ & correlations \\
\hline Active engagement & $3.82(1.15)$ & $3.75(0.98)$ & 0.90 \\
Perceptual abilities & $5.08(1.00)$ & $5.04(0.92)$ & 0.87 \\
Musical training & $2.86(1.40)$ & $2.83(1.39)$ & 0.94 \\
Singing abilities & $3.99(1.29)$ & $4.10(1.12)$ & 0.84 \\
Emotions & $5.49(0.85)$ & $5.43(0.80)$ & 0.84 \\
General musical sophistication & $3.55(1.06)$ & $3.84(0.96)$ & 0.92 \\
\hline
\end{tabular}

Gold-MSP-P: Goldsmiths Musical Sophistication Index, Portuguese version; M: mean; SD: standard deviation.

suggesting that there is no large departure from normality in the data (Curran, West, \& Finch, 1996; see online Appendix D for item-wise summary statistics).

\section{Confirmatory factor analysis}

The confirmatory factor analysis indicated a satisfactory to good fit between the model and the observed data (Cole, 1987; Hu \& Bentler, 1999; Steiger, 1989): $\chi^{2}(627)=1615.56, p<0.001$; $C F I=0.86 ; T L I=0.84, R M S E A=0.06, S R M R=0.06$. These fit values are similar to those of the replication sample reported in Müllensiefen et al. (2014) and of the German translation of the Gold-MSI in Schaal et al. (2014).

\section{Test-retest reliability}

As can be seen in Table 3, Gold-MSI-P scores were stable from the first to the second administration, and all test-retest correlations were very high (range from 0.84 to 0.94 ), suggesting very good intra-participant stability over time (four weeks). We have additionally examined internal consistency for the retest sample, and could confirm that all subscales possess acceptable to good estimates across all values (see online Appendix E).

\section{Socio-demographic correlates}

We examined how the Gold-MSI-P relates to age, sex, education, and SES. These results are summarized in Table 4. Evidence was found for an association between increasing age and lower scores across all Gold-MSI-P subscales and in the general musical sophistication factor. As for sex, no evidence for differences between men and women was found, except for the singing abilities and emotion subscales, in which women scored higher than men. Small size correlations, but yet significant, were also found with SES and education. Higher SES was generally associated with higher musical sophistication across subscales, with the amount of evidence being particularly strong for active engagement and emotions (note that correlations are negative because higher values in the ESeC indicate lower SES). Higher education was associated with higher musical sophistication, particularly for the subscales "active engagement," "emotions," and "perceptual abilities," as well as for the general sophistication factor. Note that the associations between SES/education and the musical training subscale, in particular, did not reach significance, and therefore did not replicate the findings observed with the German sample (Schaal et al., 2014). 
Table 4. Demographic and socioeconomic correlates of the Gold-MSI-P.

\begin{tabular}{lcccccc}
\hline & $\begin{array}{l}\text { Active } \\
\text { engagement }\end{array}$ & $\begin{array}{l}\text { Perceptual } \\
\text { abilities }\end{array}$ & $\begin{array}{l}\text { Musical } \\
\text { training }\end{array}$ & $\begin{array}{l}\text { Singing } \\
\text { abilities }\end{array}$ & Emotions & $\begin{array}{l}\text { General } \\
\text { sophistication }\end{array}$ \\
\hline Age & $-0.36^{* *}$ & $-0.30^{* *}$ & $-0.27^{* *}$ & $-0.30^{* *}$ & $-0.45^{* *}$ & $-0.36^{* *}$ \\
Gender & $>100$ & $>100$ & $>100$ & $>100$ & $>100$ & $>100$ \\
SES & 2.11 & 0.63 & -0.05 & $3.46^{* *}$ & $3.03^{*}$ & 2.02 \\
& 1.04 & 0.15 & 0.13 & 35.77 & 9.71 & 0.88 \\
Education & $-0.12^{*}$ & $-0.11^{*}$ & -0.09 & -0.08 & $-0.15^{* *}$ & $-0.11^{*}$ \\
& 16.69 & 8.97 & 1.79 & 1.08 & $>100$ & 6.46 \\
& $0.13^{* *}$ & 0.09 & 0.06 & 0.07 & $0.12^{*}$ & $0.10^{*}$ \\
\hline
\end{tabular}

Note: $N=408$ for all correlations, except for those involving SES, where $n=37 \mathrm{I}_{\text {. }} B F_{10}$ values are indicated in italics. For Age, SES and Education, values represent correlation coefficients; for Gender, they represent $t$ values.

*Corrected $p<0.05 ;{ }^{* *} p<0.001$.

Gold-MSP-P: Goldsmiths Musical Sophistication Index, Portuguese version; SES: socio-economic status.

\section{Personality and music preferences correlates}

Associations between the Gold-MSI-P and personality and music preferences are summarized in Table 5. These correlations were conducted on residual values, after having removed the effects of socio-demographic variables (age, sex, education, SES), to ensure that the identified associations cannot be attributed to these factors. As for personality, "openness" is the trait for which the evidence for links with musical sophistication was strongest: participants scoring higher on openness scored higher across all Gold-MSI-P subscales and on the general musical sophistication factor. Associations were also found for extraversion, with higher levels of extraversion being linked with higher singing abilities, active engagement, emotions, and general musical sophistication (anecdotal evidence was also found for perceptual abilities). As for the remaining traits, no clear evidence (i.e., $B F_{10}>3$ ) was found for associations other than the one between agreeableness and perceptual abilities.

Regarding music preferences, we found an association between enjoying music (i.e., providing higher ratings on the STOMP) and scoring higher on the general sophistication factor. The amount of evidence was decisive for all dimensions/genres except for energetic and rhythmic, for which the effect was in the same direction but weaker (see Table 5).

Enjoying music was also associated with the "active engagement" and "emotions" subscales of the Gold-MSI-P, regardless of the genre (evidence for these associations was substantial to decisive in all cases). For the remaining subscales, more selective associations with specific musical genres were found: musical training was more strongly related to preferences for reflective and complex music, as predicted; singing abilities were more strongly related to preferences for upbeat and conventional music; and perceptual abilities were more strongly related to preferences for reflective and complex, and intense and rebellious music.

\section{Discussion}

The current paper describes the development and validation of the Portuguese version of the Gold-MSI, a self-report measure of musical sophistication in the general population. It also examines the socio-demographic, personality, and music preferences correlates of this measure. Converging evidence from several indices established that the newly developed Gold-MSI-P displays appropriate internal consistency (Cronbach's $\alpha$, Guttman's $\lambda 6$, McDonald's $\omega$, 
Table 5. Correlations between the Gold-MSI-P, personality traits (as measured by the BFI), and music preferences (as measured by the STOMP).

\begin{tabular}{|c|c|c|c|c|c|c|c|}
\hline & $M(S D)$ & $\begin{array}{l}\text { Active } \\
\text { engagement }\end{array}$ & $\begin{array}{l}\text { Perceptual } \\
\text { abilities }\end{array}$ & $\begin{array}{l}\text { Musical } \\
\text { training }\end{array}$ & $\begin{array}{l}\text { Singing } \\
\text { abilities }\end{array}$ & Emotions & $\begin{array}{l}\text { General } \\
\text { sophistication }\end{array}$ \\
\hline \multicolumn{8}{|l|}{ Personality } \\
\hline \multirow[t]{2}{*}{ Extraversion } & \multirow[t]{2}{*}{$3.38(0.78)$} & $0.17^{*}$ & 0.13 & 0.06 & $0.21^{*}$ & $0.18^{*}$ & 0.16 \\
\hline & & 15.70 & 1.56 & 0.13 & $>100$ & 21.37 & 8.18 \\
\hline \multirow[t]{2}{*}{ Agreeableness } & \multirow[t]{2}{*}{$3.95(0.48)$} & 0.12 & 0.15 & 0.10 & 0.08 & 0.11 & 0.14 \\
\hline & & 0.78 & 3.71 & 0.34 & 0.23 & 0.52 & 2.22 \\
\hline \multirow[t]{2}{*}{ Conscientiousness } & \multirow{2}{*}{$3.71(0.64)$} & -0.04 & 0.00 & -0.12 & 0.00 & -0.07 & -0.07 \\
\hline & & 0.09 & 0.07 & 0.78 & 0.07 & 0.18 & 0.16 \\
\hline \multirow[t]{2}{*}{ Neuroticism } & \multirow[t]{2}{*}{$2.95(0.84)$} & -0.11 & -0.11 & -0.12 & -0.11 & -0.09 & -0.13 \\
\hline & & 0.51 & 0.47 & 0.71 & 0.64 & 0.32 & 1.60 \\
\hline \multirow[t]{2}{*}{ Openness } & \multirow[t]{2}{*}{$3.57(0.66)$} & $0.43^{* *}$ & $0.37^{* *}$ & $0.25^{* *}$ & $0.30^{* *}$ & $0.46^{* *}$ & $0.39^{* *}$ \\
\hline & & $>100$ & $>100$ & $>100$ & $>100$ & $>100$ & $>100$ \\
\hline \multicolumn{8}{|l|}{ Music preferences } \\
\hline \multirow{2}{*}{$\begin{array}{l}\text { Reflective and } \\
\text { complex }\end{array}$} & \multirow[t]{2}{*}{$4.34(1.12)$} & $0.28^{* *}$ & $0.24^{* *}$ & $0.19^{*}$ & 0.13 & $0.37^{* *}$ & $0.26^{* *}$ \\
\hline & & $>100$ & $>100$ & 34.38 & 1.29 & $>100$ & $>100$ \\
\hline \multirow{2}{*}{$\begin{array}{l}\text { Intense and } \\
\text { rebellious }\end{array}$} & \multirow[t]{2}{*}{$4.00(1.30)$} & $0.38^{* *}$ & $0.20^{*}$ & 0.10 & 0.16 & $0.32^{* *}$ & $0.23^{* *}$ \\
\hline & & $>100$ & 87.22 & 0.34 & 6.50 & $>100$ & $>100$ \\
\hline \multirow{2}{*}{$\begin{array}{l}\text { Upbeat and } \\
\text { conventional }\end{array}$} & \multirow[t]{2}{*}{$4.33(0.99)$} & 0.16 & 0.16 & 0.16 & $0.19^{*}$ & $0.18^{*}$ & $0.21^{*}$ \\
\hline & & 5.35 & 7.33 & 6.41 & 35.53 & 16.80 & $>100$ \\
\hline \multirow{2}{*}{$\begin{array}{l}\text { Energetic and } \\
\text { rhythmic }\end{array}$} & \multirow[t]{2}{*}{$3.95(1.27)$} & $0.29^{* *}$ & 0.15 & 0.00 & 0.09 & $0.26^{* *}$ & 0.14 \\
\hline & & $>100$ & 2.62 & 0.07 & 0.29 & $>100$ & 2.19 \\
\hline
\end{tabular}

Note: $n=359$ (for $\mathrm{BFI}$ ) and $n=349$ (for STOMP). $B F_{10}$ values are given in italics.

*Corrected $p<0.05 ;{ }^{* * *} p<0.00$ I.

Gold-MSP-P: Goldsmiths Musical Sophistication Index, Portuguese version; BFI: Big-Five Inventory; STOMP: Short Test of Music Preferences; M: mean; SD: standard deviation.

inter-item correlation, and mean item-total correlations), and an examination of test-retest reliability established that this measure is highly stable over time. This was observed for all subscales and for the general musical sophistication factor. Additionally, a confirmatory factor analysis showed fit values that are satisfactory and similar to those reported in previous work with the English (Müllensiefen et al., 2014) and German Gold-MSI (Schaal et al., 2014).

We found that several socio-demographic variables are associated with individual differences in the Gold-MSI, although these were mostly small size correlations. In particular, younger participants, those with higher education levels, and those from higher socioeconomic classes, tend to report higher musical sophistication. In general, this pattern extends to the Portuguese sample the findings previously obtained with the English (Müllensiefen et al., 2014) and German samples (Schaal et al., 2014). Sex differences, on the other hand, were restricted to two of the five subscales and were not seen for the general sophistication index. This confirms the observation by Müllensiefen et al. (2014) that this variable is less predictive of musical sophistication than other socio-demographic variables. It is currently unclear why we did not replicate the association between SES/education and the musical training subscale observed with the German sample (Schaal et al., 2014; such association was left unexplored in the original English study). A possible explanation is that the distribution of education and SES in our sample was relatively narrow, with many participants being highly educated and from high socioeconomic classes. 
As for personality, consistent with previous work (Müllensiefen et al., 2014; Greenberg et al., 2015), we observed that higher Gold-MSI scores correlate with higher levels of openness and extraversion. The association with openness, in particular, is in line with the fact that this personality trait has been associated with musical engagement and with aesthetic and emotional responses to music (e.g., McManus \& Furnham, 2006; Vuoskoski \& Eerola, 2011).

Finally, we report, for the first time, associations between musical sophistication and music preferences. Individuals scoring higher in the general musical sophistication factor reported enjoying music more, and this was observed for all music dimensions covered by the STOMP (reflective and complex; intense and rebellious; upbeat and conventional; and at trend-level for energetic and rhythmic music). This association with general musical sophistication is potentially mostly driven by the links with the active engagement and emotions subscales, as these were the only two subscales for which correlations with all music dimensions were also observed. A possible interpretation is that stronger preferences for particular musical genres could motivate individuals to engage more in music-related activities and to display musicrelated emotion behaviors, resulting in more sophisticated musical skills and behaviors. The direction of causes and effects of these associations will need to be examined in future research, however. Another interesting finding was that the musical training and perceptual abilities subscales were more strongly related to preferences for reflective and complex music, a dimension that includes classical music, blues, folk, and jazz. This could suggest that more developed perceptual systems (namely, via training) could contribute to a higher appreciation of more intricate music, or it could also reflect the fact that musical training typically emphasizes classical/complex music, which could contribute to stronger preferences for these genres over time (e.g., Getz, Marks, \& Roy, 2014; Hargreaves, Comber, \& Colley, 1995). Future studies should further examine how musical sophistication relates to music preferences by using a more comprehensive assessment of music preferences than the one used here, and focusing on the developmental trajectories of both preferences for musical genres and musical skills and behaviors.

To conclude, the present study makes available a new tool for research on music behaviors and skills with Portuguese speaking participants - the Gold-MSI-P. It provides support for the validity and reliability of this tool and contributes to advancing general knowledge on the correlates of musical sophistication, that is, the socio-demographic, personality, and music preferences variables. The Gold-MSI-P is freely available, and it provides an easy-to-use measure that will be useful across a wide range of contexts, from cross-cultural work to neuroscience, music psychology, and education research.

\section{Acknowledgements}

We thank Andreia Nunes and Teresa Limpo for helping with data collection.

\section{Declaration of conflicting interests}

The author(s) declared no potential conflicts of interest with respect to the research, authorship, and/or publication of this article.

\section{Funding}

The author(s) disclosed receipt of the following financial support for the research, authorship, and/or publication of this article: This work was supported by a FCT Investigator Grant from the Portuguese Foundation for Science and Technology (IF/00172/2015), awarded to C. F. Lima. It was also supported by the Center for Psychology at University of Porto under grants UID/PSI/00050/2013 and POCI01-0145-FEDER-007294. 


\section{Note}

1. We aimed for recruiting the largest possible sample of participants. However, we also determined that a sample of $N=400$ would be sufficient to detect even small correlational effects with an alpha level of 0.05 and a power of 0.80 , e.g., $r=0.14$, found by Schaal et al. (2014) with the German version of the Gold-MSI.

\section{References}

Bauer, A., Jaeger, M., Thorne, J., Bendixen, A., \& Debener, S. (2015). The auditory dynamic attending theory revisited: A closer look at the pitch comparison task. Brain Research, 1626, 198-210.

Bigand, E., \& Poulin-Charronnat, B. (2006). Are we "experienced listeners"? A review of the musical capacities that do not depend on formal musical training. Cognition, 100(1), 100-130.

Bleichner, M., Mirkovic, B., \& Debener, S. (2016). Identifying auditory attention with ear-EEG: cEEGrid versus high-density cap-EEG comparison. Journal of Neural Engineering, 13(6), 066004.

Brito-Costa, S., Bem-Haja, P., Moisão, A., Alberty, A., Castro, F. V., \& De Almeida, H. (2015). Psychometric properties of Portuguese version of Big Five Inventory (BFI). International Journal of Developmental and Educational Psychology [INFAD Revista de Psicología], 1(2), 83-94.

Churchill, G. (1979). A paradigm for developing better measures of marketing constructs. Journal of Marketing Research, 16(1), 64-73.

Clark, L., \& Watson, D. (1995). Constructing validity: Basic issues in objective scale development. Psychological Assessment, 7(3), 309-319.

Coffey, E., Mogilever, N., \& Zatorre, R. (2017). Speech-in-noise perception in musicians: A review. Hearing Research, 352, 49-69.

Cole, D. (1987). Utility of confirmatory factor analysis in test validation research. Journal of Consulting and Clinical Psychology, 55(4), 584-594.

Cronbach, L. (1951). Coefficient alpha and the internal structure of tests. Psychometrika, 16(3), 297-334.

Curran, P., West, S., \& Finch, J. (1996). The robustness of test statistics to nonnormality and specification error in confirmatory factor analysis. Psychological Methods, 1(1), 16-29.

Field, A. (2005). Discovering statistics using SPSS (3rd ed.). London: SAGE.

Getz, L., Marks, S., \& Roy, M. (2014). The influence of stress, optimism, and music training on music uses and preferences. Psychology of Music, 42(1), 71-85.

Greenberg, D., Müllensiefen, D., Lamb, M., \& Rentfrow, P. (2015). Personality predicts musical sophistication. Journal of Research in Personality, 58, 154-158.

Guttman, L. (1945). A basis for analyzing test-retest reliability. Psychometrika, 10(4), 255-282.

Hadley, L., Sturt, P., Eerola, T., \& Pickering, M. (2018). Incremental comprehension of pitch relationships in written music: Evidence from eye movements. Quarterly Journal of Experimental Psychology, 71(1), 211-219.

Hambleton, R. K. (2005). Issues, designs, and technical guidelines for adapting tests into multiple languages and cultures. In R. K. Hambleton, P. Merenda, \& C. D. Spielberger (Eds.), Adapting educational and psychological tests for cross-cultural assessment (pp. 3-38). Mahwah, NJ: Lawrence Erlbaum.

Hansen, N., Vuust, P., \& Pearce, M. (2016). "If you have to ask, you'll never know": Effects of specialized stylistic expertise on predictive processing of music. PLoS ONE, 11(10), e0163584.

Hargreaves, D., Comber, C., \& Colley, A. (1995). Effects of age, gender, and training on musical preferences of British secondary school students. Journal of Research in Music Education, 43(3), 242-250.

Herholz, S., \& Zatorre, R. (2012). Musical training as a framework for brain plasticity: Behavior, function, and structure. Neuron, 76(3), 486-502.

Hu, L., \& Bentler, P. (1999). Cutoff criteria for fit indexes in covariance structure analysis: Conventional criteria versus new alternatives. Structural Equation Modeling, 6(1), 1-55.

Jakubowski, K., Farrugia, N., \& Stewart, L. (2016). Probing imagined tempo for music: Effects of motor engagement and musical experience. Psychology of Music, 44(6), 1274-1288.

Jakubowski, K., Halpern, A., Grierson, M., \& Stewart, L. (2015). The effect of exercise-induced arousal on chosen tempi for familiar melodies. Psychonomic Bulletin \& Review, 22(2), 559-565. 
Jarosz, A., \& Wiley, J. (2014). What are the odds? A practical guide to computing and reporting Bayes factors. The Journal of Problem Solving, 7(1), 2-9.

JASP Team. (2017). JASP (Version 0.8.4) [computer software]. https://jasp-stats.org/download/.

Jeffreys, H. (1961). Theory of probability (3rd ed.). Oxford, UK: Oxford University Press.

John, O. P., \& Srivastava, S. (1999). The Big Five trait taxonomy: History, measurement, and theoretical perspectives. In L. A. Pervin \& O. P. John (Eds.), Handbook of personality: Theory and research (pp. 102-138). New York, NY: Guilford Press.

Lima, C., \& Castro, S. (2011). Speaking to the trained ear: Musical expertise enhances the recognition of emotions in speech prosody. Emotion, 11(5), 1021-1031.

McCrae, R., \& Costa, P. (1987). Validation of the five-factor model of personality across instruments and observers. Journal of Personality and Social Psychology, 52(1), 81-90.

McManus, I., \& Furnham, A. (2006). Aesthetic activities and aesthetic attitudes: Influences of education, background and personality on interest and involvement in the arts. British Journal of Psychology, 97(4), 555-587.

Moreno, S., \& Bidelman, G. (2014). Examining neural plasticity and cognitive benefit through the unique lens of musical training. Hearing Research, 308, 84-97.

Müllensiefen, D., Gingras, B., Musil, J., \& Stewart, L. (2014). The musicality of non-musicians: An index for assessing musical sophistication in the general population. PLoS ONE, 9(2), e89642.

Rentfrow, P., \& Gosling, S. (2003). The do re mi's of everyday life: The structure and personality correlates of music preferences. Journal of Personality and Social Psychology, 84(6), 1236-1256.

Revelle, W., \& Zinbarg, R. (2009). Coefficients alpha, beta, omega, and the glb: Comments on Sijtsma. Psychometrika, 74(1), 145-154.

Rose, D., \& Harrison, E. (2007). The European socio-economic classification: A new social class schema for comparative European research. European Societies, 9(3), 459-490.

Rosseel, Y. (2012). lavaan: An R package for structural equation modeling. Journal of Statistical Software, $48(2), 1-36$.

Schaal, N., Banissy, M., \& Lange, K. (2015). The rhythm span task: Comparing memory capacity for musical rhythms in musicians and non-musicians. Journal of New Music Research, 44(1), 3-10.

Schaal, N., Bauer, A., \& Müllensiefen, D. (2014). The Gold-MSI: Replication and validation of a questionnaire instrument to measure musical experience based on a German sample [Der Gold-MSI: Replikation und validierung eines fragebogeninstrumentes zur messung musikalischer erfahrenheit anhand einer deutschen stichprobe]. Musicae Scientiae, 18(4), 423-447.

Schaal, N., Krause, V., Lange, K., Banissy, M., Williamson, V., \& Pollok, B. (2015). Pitch memory in nonmusicians and musicians: Revealing functional differences using transcranial Direct Current Stimulation. Cerebral Cortex, 25(9), 2774-2782.

Steiger, J. H. (1989). EzPATH: Causal modeling. Evanston, IL: SYSTAT.

Taruffi, L., Allen, R., Downing, J., \& Heaton, P. (2017). Individual differences in music-perceived emotions: The influence of externally oriented thinking. Music Perception, 34(3), 253-266.

Vuoskoski, J., \& Eerola, T. (2011). Measuring music-induced emotion: A comparison of emotion models, personality biases, and intensity of experiences. Musicae Scientiae, 15(2), 159-173.

Wagenmakers, E., Love, J., Marsman, M., Jamil, T., Ly, A., Verhagen, J., ... Morey, R. D. (2017). Bayesian inference for psychology. Part II: Example applications with JASP. Psychonomic Bulletin \& Review, 25(1), 58-76.

Wagenmakers, E., Verhagen, J., \& Ly, A. (2016). How to quantify the evidence for the absence of a correlation. Behavior Research Methods, 48(2), 413-426.

Zinbarg, R., Revelle, W., Yovel, I., \& Li, W. (2005). Cronbach's $\alpha$, Revelle's $\beta$, and McDonald's $\omega H$ : Their relations with each other and two alternative conceptualizations of reliability. Psychometrika, 7O(1), 123-133.

Zweigenhaft, R. L. (2008). A do re mi encore: A closer look at the personality correlates of music preferences. Journal of Individual Differences, 29(1), 45-55. 